\title{
Validation of Fluorescent SSCP Analysis for Sensitive Detection of p53 Mutations
}

BioTechniques 28:986-992 (May 2000)

\author{
L. Moore, T. Godfrey, C. Eng, \\ A. Smith, R. Ho and \\ F.M. Waldman \\ University of California Berke- \\ ley, School of Public Health, \\ Berkeley, CA, USA
}

\section{INTRODUCTION}

The p53 tumor suppressor protein is involved in many important cellular processes that include apoptosis, gene transcription, DNA repair, genomic stability and cell cycle control (2). Therefore, it is not surprising that mutation of the p53 gene is the most common genetic alteration in human cancers. Specific patterns of $\mathrm{p} 53$ mutations are thought to result from different mechanisms, and mutations in different protein domains are associated with varying functional alterations (5). By characterizing the frequency, type and position of mutations in the p53 gene, inferences may be made regarding potential sources of mutation in the environment.

The p53 gene contains 11 exons and 393 amino acids (7). Of these, exons 5-8 contain "hot spots" for mutation. Such preferred sites reside in evolutionarily conserved regions of the gene, depending on their functional importance (3). DNA sequencing is required for precise identification of mutations, but this can be labor intensive and expensive. To overcome these problems, screening tests are frequently used to preselect samples with possible mutations for subsequent sequencing.

While new methods for mutation detection are constantly being developed, single strand conformation polymorphism (SSCP) (9) is still the most commonly cited technique. The visualization of DNA strands is usually carried out by isotopic labeling of PCR primers, followed by autoradiography or staining the gel with agents such as ethidium bromide or silver. None of these visualization methods is capable of distinguishing between the two DNA strands, and the resulting data are often hard to interpret, especially when complicated by more than one stable conformation of one or both strands.

Recently, several authors have used fluorescent labeling to uniquely identify sense and antisense DNA strands $(1,4,8,10)$. Combined with automated DNA sequencers for accurate temperature control and multicolor fluorescence detection, these features have the potential to significantly improve the $70 \%-90 \%$ mutation detection rates previously reported $(8,9)$. The system also includes internal size standards in each lane and thus allows small mobility shifts to be reliably detected.

Given the importance of p53 mutation detection, any improvements of current methods will be useful, especially in screening multiple tumor samples for clinical and molecular epidemiological studies. Here, we report the optimization of a fluorescence-based SSCPPCR method that overcomes most of the difficulties associated with conventional SSCP procedures and allows rapid and accurate mutation screening of $\mathrm{p} 53$ exons 5-8. Moreover, sensitivity and specificity (the percentage of true mutants/all mutant samples and the percentage of true normals/all normal samples, respectively) of SSCP screeningthe critical factors that strongly influence interpretation of p53 mutation studies - have been measured using previously characterized (6) mutant cell lines and normal tissues. Mixing experiments using heterozygous mutant and normal DNAs were also conducted to determine the limits of mutation detection in heterogeneous samples.

\section{MATERIALS AND METHODS}

\section{Cell Lines}

Representing unique mutations and amino acid substitutions throughout exons 5-8, 21 cell lines were identified in the International Agency for Cancer Research's p53 database (reference 6, which is also available electronically at 
Table 1. SSCP for Mutant Cell Lines using Optimal Conditions

\begin{tabular}{|c|c|c|c|c|c|}
\hline Exon & Cell Line & Codon & Mutation & $\begin{array}{l}\text { Sense Strand } \\
\text { (mobility shifts) }\end{array}$ & $\begin{array}{l}\text { Antisense Strand } \\
\text { (mobility shifts) }\end{array}$ \\
\hline 5 (276 bpa) & BT20 & 132 & AAG-CAG & $-a(0) b$ & $+c(-486)$ \\
\hline 5 & ST486 & 158 & CGC-CAC & $+(+74)$ & $+(157)$ \\
\hline 5 & CEM & 175 & $\begin{array}{l}\text { CGC-CAC } \\
\text { (Heterozygote) }\end{array}$ & $+(-122)$ & $+(-905)$ \\
\hline 5 & LAN1 & 182 & TGC-TGA & $+(-187)$ & $+(-52)$ \\
\hline 5 & SW1116 & 159 & GCC-GAC & $+(+449)$ & $+(-397)$ \\
\hline 5 & SKBR3 & 175 & CGC-CAC & $+(-112)$ & $+(-927)$ \\
\hline \multicolumn{4}{|l|}{ Sensitivity } & \multicolumn{2}{|c|}{$6 / 6=100 \%$} \\
\hline $6(165 \mathrm{bp})$ & Raji & 213 & $\begin{array}{l}\text { CGA-CAA } \\
\text { (Heterozygote) }\end{array}$ & $+(-65)$ & $-(0)$ \\
\hline 6 & Calu6 & 196 & CGA-TGA & $+(-258)$ & $+(-70)$ \\
\hline 6 & DU145 & 223 & ССТ-СТT & $+(+132)$ & $-(0)$ \\
\hline 6 & T47D & 194 & CTT-TTT & $+(-63)$ & $+(+47)$ \\
\hline 6 & SKLU1 & 193 & CAT-CGT & $-(0)$ & $-(0)$ \\
\hline \multicolumn{4}{|l|}{ Sensitivity } & \multicolumn{2}{|c|}{$4 / 5=80 \%$} \\
\hline 7 (182 bp) & Raji & 234 & TAC-CAC & $-(0)$ & $+(-74)$ \\
\hline 7 & $\mathrm{RD}$ & 248 & CGG-TGG & $+(-182)$ & $+(+154)$ \\
\hline 7 & CEM & 248 & CGG-CAG & $+(+217)$ & $+(-102)$ \\
\hline 7 & BT549 & 249 & AGG-AGC & $+(-223)$ & $+(-284)$ \\
\hline 7 & Ramos & 254 & ATC-GAC & $+(+891)$ & $+(+753)$ \\
\hline 7 & DAOY & 242 & TGC-TTC & $+(+218)$ & $+(+167)$ \\
\hline \multicolumn{4}{|l|}{ Sensitivity } & \multicolumn{2}{|c|}{$6 / 6=100 \%$} \\
\hline 8 (237 bp) & MDA231 & 280 & AGA-AAA & $+(+77)$ & $-(0)$ \\
\hline 8 & BT474 & 285 & GAG-AAG & $+(+103)$ & $+(-47)$ \\
\hline 8 & DU145 & 273 & $\begin{array}{l}\text { CGT-CAT } \\
\text { (Heterozygote) }\end{array}$ & $+(+73)$ & $+(+68)$ \\
\hline 8 & PANC1 & 274 & GTT-TTTd & $-(0)$ & $-(0)$ \\
\hline \multicolumn{4}{|l|}{ Sensitivity } & \multicolumn{2}{|c|}{$3 / 3=100 \%$} \\
\hline $\begin{array}{l}\text { Sensitivity fo } \\
a_{-} \text {indicates } \\
\text { b indicates th } \\
c_{+} \text {indicates } \\
d_{\text {this mutatio }}\end{array}$ & $\begin{array}{l}\text { Is } \\
\text { ft seen } \\
\text { r of mobility st } \\
\text { was present, } \\
\text { t confirmed by }\end{array}$ & $\begin{array}{l}\text { scans) an } \\
\text { cing }\end{array}$ & on with respect to & d-type & $95 \%$ \\
\hline
\end{tabular}

www.ftp.embl-heidelberg.de/pub/databases/p53) (Table 1). Cell lines, readily available from the cell culture facility at the University of California at San Francisco (UCSF) and containing different types of mutations in exons 5-8, were used. Two normal DNA samples were obtained from healthy donors' blood, and eight samples were from frozen normal lung tissue (supplied by Dr. David Jablons at UCSF). DNA was extracted using the Wizard ${ }^{\circledR}$ genomic DNA purification kit according to the manufacturer's instructions (Promega, Madison, WI, USA).

\section{PCR}

PCR was carried out in a GeneAmp $^{\circledR}$ PCR System 9700 thermal cycler (PE Biosystems, Foster City, CA, USA) in $25-\mu \mathrm{L}$ reaction volumes. Each
PCR contained $2.5 \mathrm{mM} \mathrm{MgCl}_{2}, 0.2$ mM each dNTP, 0.625 U Taq Gold ${ }^{\circledR}$ polymerase, $1 \times$ PCR Buffer II (both from PE Biosystems), $0.4 \mu \mathrm{M}$ of sense and antisense fluorescently labeled primers (Table 2) and 20-40 ng genomic DNA. PCR cycling conditions were as follows: $95^{\circ} \mathrm{C}$ for $12 \mathrm{~min}$ followed by 32 cycles at $95^{\circ} \mathrm{C}$ for $15 \mathrm{~s}, 58^{\circ} \mathrm{C}$ for $15 \mathrm{~s}, 72^{\circ} \mathrm{C}$ for $30 \mathrm{~s}$ and a final extension at $72^{\circ} \mathrm{C}$ for $10 \mathrm{~min}$. Table 2 shows the 
Table 2. Primer Sequences Used for SSCP and Sequencing

\begin{tabular}{|llll|}
\hline Exon & SSCP PCR Primers & \multicolumn{1}{c|}{ Sequencing PCR Primersa } & \multicolumn{1}{c|}{ Sequencing Primers } \\
\hline E5 forward & FAM-CCA GTT GCT TTA & TGT CGT CTC TCC AGC CCC AG & TGT CGT CTC TCC AGC CCC AG \\
& TCT GTT CA & & \\
E5 reverse & TET- TGT CGT CTC TCC & CCA GTT GCT TTA TCT GTT CA & CCA GTT GCT TTA TCT GTT CA \\
& AGC CCC AG & & \\
E6 forward & FAM- GCT GCT CAG ATA & M13(f)-CTC TGA TTC CTC ACT & TGT AAA ACG ACG \\
& GCG ATG GTG & GAT TG & GCC AGT \\
E6 reverse & TET-GCC ACT GAC AAC & M13(r)- CAG AGA CCC CAG TTG & CAG GAA ACA GCT \\
& CAC CCT TAA C & CAAAC & ATG ACC \\
E7 forward & FAM-CCA AGG CGC ACT & M13(f)-CCA AGG CGC ACT GGC & TGT AAA ACG ACG \\
& GGC CTC & CTC & GCC AGT \\
E7 reverse & TET-AGT GTG CAG GGT & M13(r)-AGT GTG CAG GGT GGC & CAG GAA ACA GCT \\
& GGC AAG & AAG & ATG ACC \\
E8 forward & FAM- CCT TAC TGC CTC & M13(f)-CCT TAC TGC CTC TTG & TGT AAA ACG ACG \\
& TTG CTT C & CTT C & GCC AGT \\
E8 reverse & TET-TGA ATC TGA GGC & M13(r)-TGA ATC TGA GGC ATA & CAG GAA ACA GCT \\
& ATA ACT GC & ACTGC & ATG ACC \\
aM13(f)-forward, TGTAAAACGACGGCCAGT; M13(r)-reverse, CAGGAACAGCTATGACC
\end{tabular}

PCR primers and fluorescent labels used for each exon. All primers were purchased from Life Technologies (Rockville, MD, USA).

\section{SSCP}

A 5.5- $\mu \mathrm{L}$ loading mixture was prepared with $1 \mu \mathrm{L}$ PCR product, $0.5 \mu \mathrm{L}$ of GeneScan ${ }^{\circledR} 500$ size standards (PE Biosystems), $0.5 \mu \mathrm{L}$ loading dye (PE Biosystems), $0.5 \mu \mathrm{L} 100 \mathrm{mM} \mathrm{NaOH}$ and $3 \mu \mathrm{L}$ deionized formamide. The loading mixture was denatured at $95^{\circ} \mathrm{C}$ for $3 \mathrm{~min}$ and then placed immediately on ice. Then, $0.7-1 \mu \mathrm{L}$ of this sample mixture were loaded into each well of the SSCP gel. Multiple normals were electrophoresed on each gel (every 5-7 lanes) to aid data analysis in case of uneven gel performance. In addition, only the center lanes were used (30 of 36 or 40 of a 48-lane comb) to avoid uneven temperature control in the outer lanes. To determine positivity, all positive shifts reported in this paper were $>2( \pm \mathrm{SD})$ from the mean of the wild-type DNA samples electrophoresed on the same gel.

SSCP gels were cast using $36-\mathrm{cm}$ plates (PE Biosystems) and 36- or 48- well shark's-tooth combs. All gels consisted of $0.5 \times$ mutation detection enhancement (MDE) gel (BMA, Rockland, ME, USA) with $2.5 \%, 5 \%$ or $10 \%$ glycerol (Sigma, St. Louis, MO, USA) and $1 \times$ TBE (Life Technologies). The gels were polymerized with $300 \mu \mathrm{L}$ $10 \%$ ammonium persulphate and 37.5 $\mu \mathrm{L}$ TEMED per $60 \mathrm{~mL}$ gel solution. The gels were then mounted on the precooled ABI 377 sequencer, and no prerun was used before loading. Electrophoresis was performed at $15^{\circ} \mathrm{C}, 20^{\circ} \mathrm{C}$ and $25^{\circ} \mathrm{C}$. Gel cooling was provided by a VWR 1190A refrigerated water bath (VWR Scientific, West Chester, PA, USA) connected to the inlet/outlet tubes of the ABI 377 sequencer. The $2400 \mathrm{C}$ chiller module was used in the ABI collection software to override the instrument's pump and temperature control systems that were provided by the water bath instead. Gel temperature was monitored in the software status window. All gels were run at $60 \mathrm{~W}$ constant power with nonlimiting voltage $(4000 \mathrm{~V})$ and current $(60 \mathrm{~mA})$.

\section{Data Analysis}

SSCP results were analyzed using
GeneScan software with analysis procedures and settings as described by the manufacturer's ABI SSCP user guide. The GeneScan software allows test DNA data to be overlaid with data from a normal sample on the same gel to make visualization of mobility shifts easier. The sense and antisense strands were scored separately for shifts.

\section{Sequencing}

Fluorescent DNA sequencing was carried out using BigDye ${ }^{\mathrm{TM}}$ dye terminator sequencing chemistry (PE Biosystems). Primers used are shown in Table 2. Before sequencing, PCR products were purified using the PCR product presequencing kit (Amersham Pharmacia Biotech, Piscataway, NJ, USA) to remove excess primers and nucleotides. All exons were sequenced in both forward and reverse directions to confirm the presence or absence of mutations.

\section{RESULTS}

SSCP was performed on 21 cell lines with previously reported mutations (6). Table 1 shows SSCP results for the op- 
timum conditions (0.5× MDE, $2.5 \%$ glycerol, $\left.25^{\circ} \mathrm{C}\right)$. Both the sense (FAM) and antisense (TET) strands were shifted more frequently using these conditions. Overall, the sensitivity of SSCP using these conditions was $95 \%$, and there were no false positives detected in the normal DNA tested. Examples of SSCP results for each exon, a comparison of mutant cell line to normal PCR product, are presented in Figure 1. When the same samples were run at $20^{\circ} \mathrm{C}$ with $2.5 \%$ glycerol, we detected $19 / 21$ or $90.5 \%$ of mutations and were unable to detect two mutations in exon
6, codon 223 of cell line DU145 and codon 213 of cell line Raji.

When the glycerol content was increased to $5 \%$ at $20^{\circ} \mathrm{C}, 14 / 16$ or $87.5 \%$ of mutations were detected, and we were unable to detect the mutations in exon 5, codon 158 of cell line ST486 and exon 8 and codon 273 of cell line DU145. When the temperature was increased to $25^{\circ} \mathrm{C}, 14 / 15$ or $93 \%$ of mutations were detected. Using this condition, it was impossible to detect the exon 5 codon 182 mutation described in cell line LAN1. The worst results were obtained when $10 \%$ glycerol was used. At $25^{\circ} \mathrm{C}$,

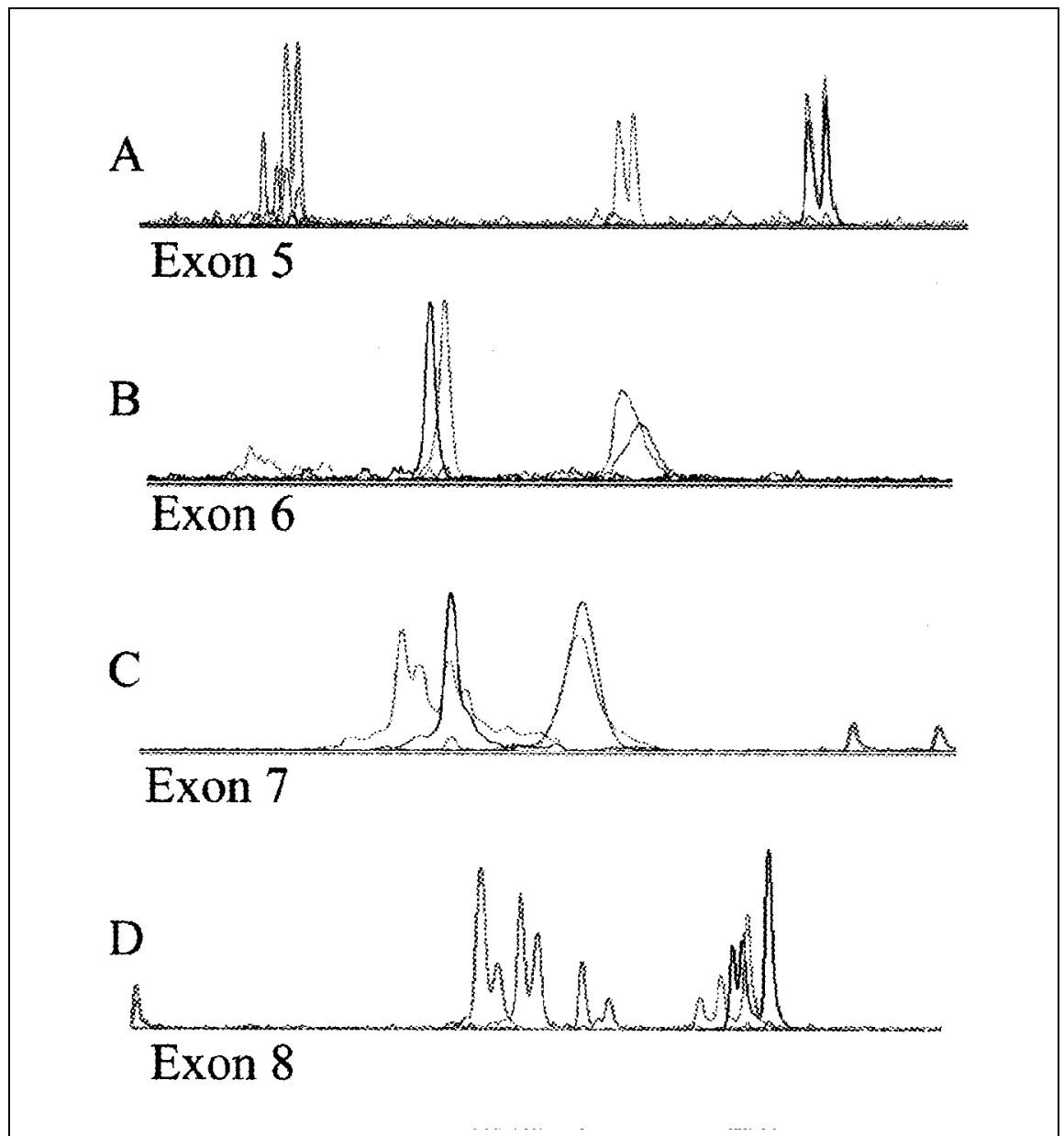

Figure 1. Fluorescent SSCP detection in cell lines. In each panel, each cell line DNA was amplified with exon-specific primers, each labeled with either FAM (sense) or TET (antisense). A normal profile was overlaid with the test profile and aligned using the internal size standards (small red peaks). In each of the panels, the normal-sense strand is labeled red-orange, and the normal-antisense strand is labeled brown. The cell line-sense strand is labeled blue, and the cell line-antisense strand is labeled green. (A) Heterozygous mutation in CEM cell line exon 5. Sense (blue) and antisense (green) strands show both shifted and unshifted peaks. (B) Homozygous mutation in T47D cell line exon 6. Shifts can be seen in both the sense (blue) and antisense (green) strands. (C) Heterozygous mutation in RAJI cell line exon 7. A shift can be detected in the antisense (green) but not the sense (blue) strand. (D) Homozygous mutation in BT474 cell line exon 8. Multiple peaks are seen for both sense and antisense strands as a result of multiple stable conformations. All peaks (sense and antisense) are shifted relative to normal control. 
$14 / 16$ or $75 \%$ of mutations were detected. Exon 6 failed in all cases with 5\% or $10 \%$ glycerol. Therefore, the results are given for only 15 or 16 cell lines.

A mutation in cell line PANC1 was not detected with any of the SSCP gel conditions. DNA sequencing showed no evidence of the mutation that was reported in the database. Sequencing of all remaining cell lines confirmed the previously reported mutations.

Mixing experiments were used to define the sensitivity of SSCP analysis in a pre-PCR mixture of mutated formalinfixed tumor and normal DNA (mixed before PCR amplification). An abnormally migrating peak was clearly seen, even in the presence of $80 \%$ and possibly even as low as $90 \%$ normal DNA (arrows, Figure 2, panels D and E).

\section{DISCUSSION}

There are numerous advantages for using multicolor fluorescent SSCP analysis compared to using radioactive labeling methods. One is that isotopes are not used. Second, all analysis is done using a computer imaging system, eliminating the need for post-electrophoresis gel handling and achieving better resolution of mobility shifts to align data from lane to lane. Third, the use of dual colors to label the individual strands allows overlapping bands to be discriminated and also allows easier interpretation of band shifts associated with specific mutations.

Recent advances in sequencing technology bring into question the general utility of SSCP analysis. However, we have found that preliminary screening for mutations with SSCP is practical and efficient, especially when conducting large studies. SSCP screening is faster and less expensive than sequencing, especially if the percentage of mutant samples is low. Furthermore, SSCP can determine which exon is mutated, and only this exon needs to be sequenced for confirmation, thus reducing the amount of sequencing required. If the sequencing reaction has low background and so is easy to interpret, then SSCP followed by sequencing in only one direction can be used. However, if the sequencing reaction contains a high background or if the sample is heterogeneous, it is opti- mal to use SSCP followed by bidirectional sequencing. Alternatively, SSCP is a sensitive method to confirm sequencing abnormalities. Similarly, SSCP could be used to confirm the presence or absence of heterozygotes initially identified by sequencing but obscured by a high background. Background in sequencing frequently results from a poor DNA template, a common occurrence when using DNA from formalin-fixed paraffin sections.

A previous study by O'Connell et al. (8) tested the MDE gel but found that optimal results were obtained with a $12 \%(\mathrm{w} / \mathrm{v})$ acrylamide $50: 1$ plus $10 \%$ (v/v) glycerol gel run at $20^{\circ} \mathrm{C}$. They noted small effects for the Daudi, exon 5 codon 153 and RD-ES, exon 8 codon 273 mutations, but large mobility shifts for other mutations in exons 7 and 8 , some of which were nearly too large to detect after $14 \mathrm{~h}$. With the addition of $15 \%$ urea to the MDE gel, a reduction was seen in the unusually large mobility shifts and samples not previously detectable in the absence of urea. In our study, we found that the MDE gel ran

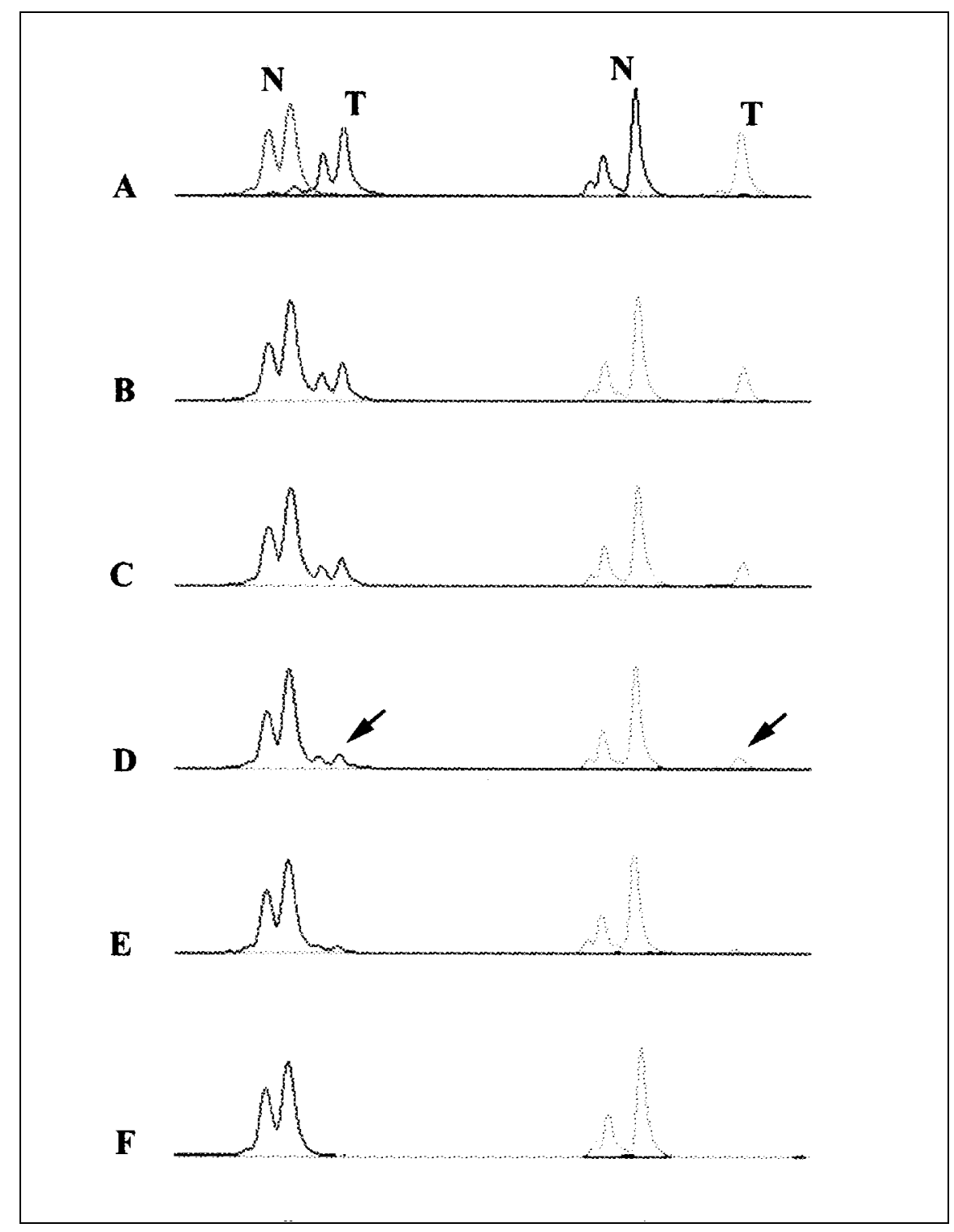

Figure 2. Mixing experiment to determine the sensitivity of mutation detection in the presence of normal DNA. (A) $100 \%$ tumor (T) and $100 \%$ normal (N) profiles overlaid. (B) $40 \%$ tumor and $60 \%$ normal. (C) 30\% tumor and 70\% normal. (D) 20\% tumor and $80 \%$ normal (E) $10 \%$ tumor and $90 \%$ normal. (F) $100 \%$ normal. Arrows indicate the tumor peaks visible even in the presence of $80 \%$ normal DNA. 
more consistently, offered greater resolution than acrylamide and was therefore more likely to detect mobility shifts. When glycerol levels were $5 \%$ or greater, we found that both consistency and resolution decreased. The worst results were obtained when $10 \%$ glycerol was used.

O'Connell et al. (8) also found considerable variability in the detection sensitivity of the seven p53 mutations analyzed using different gel conditions. In our study, 21 rather than seven cell lines, with mutations throughout exon 5-8 and 10 normal controls, were analyzed. The sensitivity of mutation detection was $95 \%$, which is higher than the 70\%-90\% mutation detection rates previously reported by some groups $(2,9)$, but lower than $100 \%$ as reported by O'Connell et al., possibly because of the large number of cell lines tested (8).

Furthermore, it was possible to detect mutant tumor DNA in the presence of $80 \%$ normal DNA. This level of sensitivity in mutation detection is important since many tumors are heterozygous or heterogeneous for $\mathrm{p} 53$ mutations, and since tumor tissue is frequently contaminated with normal cells. In such samples, the presence of a mutation would be difficult to identify by sequencing alone (especially in the presence of any sort of background), but the identification of a mutation using both fluorescent SSCP and sequencing is substantially improved. However, it should be noted that fluorescent SSCP does not allow isolation or enrichment of possible mutants for sequence analysis, which is possible with conventional SSCP.

For the cell lines analyzed here, all positive shifts reported were greater than 2 SD from the mean of the wildtype samples run on the same gel. However, when screening unknown samples for mutations, we preferred to use the SD of the normal samples only as a guide, with the final decision being made subjectively by aligning the test samples in only the closest lanes. This is because normal peaks often show a nonrandom and gradual shift from one side of the gel to the other, probably caused by slight variations in temperature or gel thickness. By aligning each test case with the two closest normal samples, it was possible to control for such variations across the gel. In our studies, because all suspected mutants are eventually sequenced, this methodology does not increase the number of false positives but slightly increases the amount of required sequencing.

In conclusion, we have further validated a new fluorescence-based SSCP method that allows fast and sensitive screening for mutations in exons 5-8 of the human p53 gene. The method uses an ABI 377 sequencer for unique color labeling of each strand and accurate alignment of lanes for better detection of mobility shifts. Because this method has greater sensitivity and specificity than other methods previously described, it is a useful tool in areas of cancer research where screening large numbers of samples for p53 mutations is desired.

\section{ACKNOWLEDGMENTS}

Support for this work was provided by grant nos. P30-ES01896 and P42ES04705, both from the National Insti- tute of Environmental Health Science, and grants from the UCSF Cancer Center. L.M. is the recipient of American Cancer Society fellowship no. PF4440.

\section{REFERENCES}

1.Boutin, P., E.H. Hani, F. Vasseur, C. Roch, B. Bailleul, J. Hager and P. Frognel. 1997. Automated fluorescent-based screening for mutation by SSCP: use of universal M13 dye primers for labeling and detection. BioTechniques 23:358-362.

2.Greenblatt, M.S., W.P. Bennett, M. Hollstein and C.C. Harris. 1994. Mutations in the p53 tumor suppressor gene: clues to cancer etiology and molecular pathogenesis. Cancer Res. 54:4855-4878.

3.Harris, C.C. Structure and function of the p53 tumor suppressor gene: clues for rational cancer therapeutic strategies. 1996. J. Natl. Cancer Inst. 88:1442-1455.

4.Hayashi, K. 1999. Recent enhancements in SSCP. Genetic Anal. 14:193-196.

5.Hollstein, M., D. Sidransky, B. Vogelstein and C.C. Harris. 1991. p53 in human cancers. Science 253:49-53.

6.Hollstein, M., K. Rice, M.S. Greenblatt, T. Soussi, R. Fuchs, T. Sorlie, E. Hovig, B. Smith-Sorensen et al. 1994. Database of p53 gene somatic mutations in human tumors and cell lines. Nucleic Acids Res. 22:3551-3555.

7.Lamb, P. and L. Crawford. 1986. Characterization of the human p53 gene. Mol. Cell. Biol. 6:1379-1385.

8.O'Connell, C.D., J. Tian, A. Juhasz, H.M. Wenz and D.H. Atha. 1998. Development of standard reference materials for diagnosis of p53 mutations: analysis by slab gel single strand conformation polymorphism. Electrophoresis 19:164-171.

9.Orita, M., H. Iwahana, H. Kanazawa, K. Hayashi and T. Sekiya. 1989. Detection of polymorphisms of human DNA by gel electrophoresis as single-strand conformation polymorphisms. Proc. Natl. Acad. Sci. USA 86:2766-2770.

10.Wenz, H.M., S. Ramachandra, C.D. O'Connell and D.H. Atha. 1998. Identification of known 553 point mutations by capillary electrophoresis using unique mobility profiles in a blinded study. Mutat. Res. 382:121-132.

Received 16 July 1999; accepted 7 December 1999.

Address Correspondence to:

Dr. Lee Moore

University of California Berkeley

School of Public Health

140 Warren Hall

Berkeley, CA 94720-7360 USA

Internet:lmoore@cc.ucsf.edu 